\title{
Retinopathy as a Component of the Shaken Baby Triad Talbert DG*
}

Institute of Reproductive and Developmental Biology, Imperial College School of Medicine, Queen Charlotte's Hospital, London, UK

\begin{abstract}
Introduction: Retinopathy forms an important component of the "Triad" of injuries in infants currently considered evidence of imposed trauma. Injuries are assumed to be due to physical shaking of the whole body of the infant. However, Valsalva Retinopathy produces the same injuries by cerebral venous hypertension in a different discipline, Ophthalmology.

Examples: Examples of Valsalva Retinopathy injuries are given, involving degrees of stress varying from weightlifting to playing the trombone and blowing up party balloons. These examples show vulnerability to excessive intraabdominal pressure varies between individuals. All these examples are in adults in whom shaking could not have occurred.

Mechanism: The fundamental hazard in Valsalva Retinopathy is Venous Hypertension caused by raised thoracoabdominal pressure from any cause. In infants this is most likely to occur during violent vomiting. In most individuals the brain is protected from excessive Superior Vena Cava pressure by valves in the inner jugular veins. In infants where these valves are defective, or even absent, any excessive venous pressure will be applied directly to the cerebral venous system. Susceptibility will depend on the development of the inner jugular vein valves in each particular case.

Conclusions: Retinal hemorrhages are not unique to SBS. Evidence of the findings of retinal haemorrhages is not "powerful supporting evidence of shaking" because similar injuries are known to result from Valsalva Retinopathy. The Retinopathy component of the triad is invalid in its present form, rendering the Triad itself valueless in court.
\end{abstract}

Keywords: Shaken baby syndrome; Valsalva retinopathy; Venous hypertension; Vomiting

\section{Introduction}

Occasionally infants present at hospital emergency departments with intracranial and intraocular bleeding but no visible external trauma to the head. Since there is no external evidence of imposed trauma, it is currently believed that these injuries result from shaking of the infant by the current carer, known as Shaken Baby Syndrome (SBS), or Non-Accidental Head Injury (NAHI) [1]. It is believed that the coincidence of three forms of injury, Intracranial (Subdural) Hemorrhage, Retinopathy, and Central Nervous System (CNS) malfunction, known as the "Triad", constitute proof of shaking [2] This article considers the validity of the retinal injury member of the triad.

In 2005 Lord Justice Gage (in the Supreme Court of Justice, Court of Appeal, England) declared the state of knowledge of Shaken Baby Syndrome [3] as... The accepted hypothesis depends on findings of a triad of intracranial injuries consisting of encephalopathy (defined as disease of the brain affecting the brain's function); subdural haemorrhages $(S D H)$ and retinal haemorrhages (RH). For many years the coincidence of these injuries in infants (babies aged between 1 month and 2 years) has been considered the hallmark of NAHI....

The Court judgement was that:-.... Although the evidence of the findings of retinal haemorrhages is powerful supporting evidence of shaking, on its own, it is not diagnostic of shaking.

The purpose of this article is to show that retinal haemorrhage is not "powerful evidence of Shaking" in any circumstances, because there is another well-known malady (Valsalva Retinopathy) that causes similar injuries but has no connection with imposed trauma.

\section{Methods}

\section{Valsalva hemorrhagic retinopathy}

Thomas Duane introduced the concept of "Valsalva Hemorrhagic
Retinopathy" at a meeting of the American Ophthalmology Society [4] in 1972. This was about the time that John Caffey introduced the concept of "Shaken Baby Syndrome" [5]. Valsalva, after whom the manoeuvre is named, devised a procedure in his studies of the ear but nowadays it is primarily used in cardiovascular studies. The patient is asked to exhale against a closed glottis and nasal passages, to raise intrathoracic pressure. This temporarily opposes circulatory return to the right atrium. Any circumstance that raises intrathoracic/abdominal pressure unintentionally is known as an Involuntary Valsalva Manoeuvre. Venous pressure rises as blood accumulates in the venous system until and unless it exceeds the intra thoracic pressure. It is this venous hypertension that produces the retinopathy.

It is proposed that in certain circumstances, excessive intracranial venous pressures produced during vomiting in Pyloric Stenosis can cause bleeding in the eyes of some cases of apparent Shaken Baby Syndrome.

\section{Examples of valsalva retinopathy}

Weight lifting: A healthy 17-year old experienced sudden visual loss in the left eye after weight lifting. Ophthalmoscopy revealed "cotton-wool" spots and superficial retinal hemorrhages in the macular and peripapillary areas [6].

*Corresponding author: Talbert DG, Institute of Reproductive and Developmental Biology, Imperial College School of Medicine, Queen Charlotte's Hospital, Du Cane Road, London W12 0NN, UK, Tel: 442089698151; E-mail: d.talbert@imperial.ac.uk

Received October 17, 2018; Accepted October 27, 2018; Published October 30, 2018

Citation: Talbert DG (2018) Retinopathy as a Component of the Shaken Baby Triad. J Trauma Treat 7: 433. doi: 10.4172/2167-1222.1000433

Copyright: (c) 2018 Talbert DG. This is an open-access article distributed under the terms of the Creative Commons Attribution License, which permits unrestricted use, distribution, and reproduction in any medium, provided the original author and source are credited. 
Lifting heavy objects: A 43-year-old male wore a new back support while lifting heavy objects. His left eye suffered a vitreous haemorrhage and a number of blood clots in the vitreous below the disc. Resolved after 1 month [7].

Carrying a heavy load: A lady who helped her neighbour carry a refrigerator down a flight of stairs suffered pure hemorrhagic preretinal retinopathy [4].

Pregnancy (coughing): A 27-year-old woman in her eighth month of pregnancy woke up with a coughing spell. She then found she could not see out of one eye. A few hours later her vision acuity was measured as $20 / 400$, yet 3 months later her vision was spontaneously back to $20 / 20[4]$.

Labor in pregnancy: A 29-year-old woman lost vision in her left eye during labor and was delivered by caesarean section. A large, dense, round preretinal hemorrhage obscured macular details. Treated with Nd: YAG laser pulses. Two weeks later normal vision had returned [8].

Vomiting after a party: A 33-year-old male who had been to a party awoke next morning with a headache. He vomited and suddenly noticed that he had lost vision in his right eye. Three weeks later his vision was measured as $20 / 100$, but after 3 months his sight had improved to $20 / 20$ [4].

Playing a wind instrument: A 50-year-old male solo trombonist

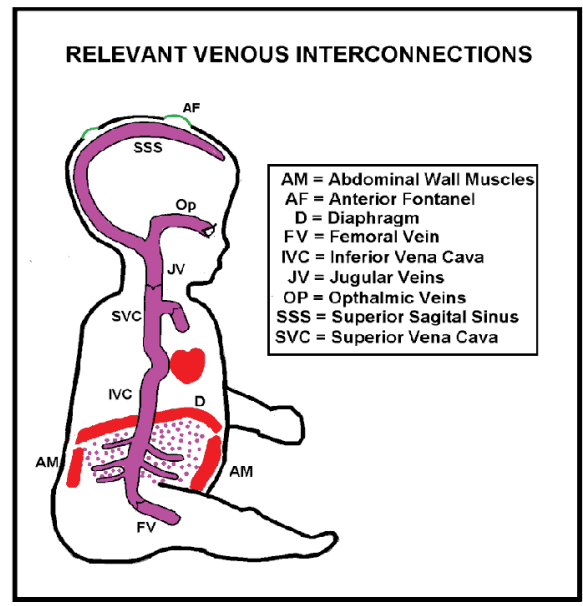

Figure 1: Structures involved in cerebral venous hypertension generation.

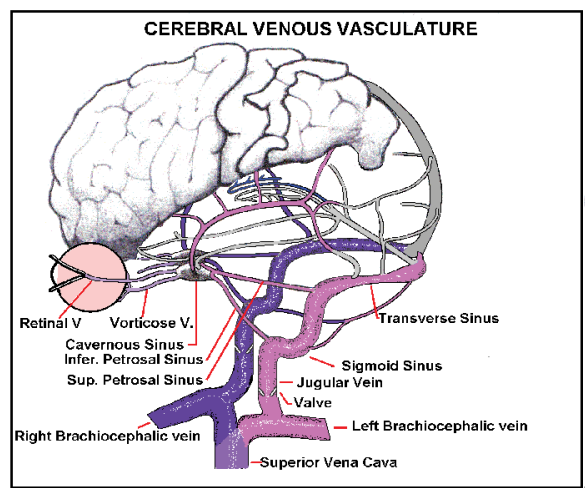

Figure 2: Some of the larger veins involved in distribution of cerebral venous hypertension if jugular vein valves fail. noticed a central scotoma in the right eye after playing a strenuous piece by Wagner. Subsequently he suffered a non-ischemic central retinal vein obstruction. These injuries recurred. He ended his professional career and had no recurrence for at least 10 years [9].

Blowing up balloons: A 47-year old man presented with an acute reduction of central acuity in his left eye whilst inflating a long party balloon. He was found to have deep and superficial retinal hemorrhages scattered in the posterior pole of the left eye. Returned to normal in 8 weeks [10].

Aerobic exercise: A 19-year-old female complained of a "dark spot" in her left eye following carrying out "Bend and Reach" exercises. (Change from legs apart standing position to a bending position low enough to reach through between the legs with both arms. This will repeatedly compress the abdomen). She suffered a slight dizziness followed by a darkish central haze in the visual field. Examination revealed a well circumscribed retinal haemorrhage near the fovea [11].

Clearly, there is a wide range of vulnerability to Valsalva Retinopathy from lifting heavy weights to vomiting after a party to blowing up party balloons. These cases are all adults so there is no possibility of shaking in the situations described.

\section{Infant valsalva retinopathy}

In infants, the SBS Technical Report [1] refers to an association of vomiting with SBS in a period preceding an SBS incident: $A$ victim of sublethal shaking may have a history of poor feeding, vomiting, lethargy, and or irritability occurring for days or weeks

In most infants, with adequate valves in their inner jugular veins to protect their brains, vomiting is relatively harmless. However, most adults can blow up balloons, play wind instruments, or vomit after a party without temporary loss of sight. To investigate what is different in these individuals it is necessary to understand how hypertensive cerebral venous pressures arise and how they act (Figure 1).

\section{Discussion}

\section{Vomiting (A mechanism generating venous hypertension)}

The vomiting act has two phases, Retching and Expulsive [12]. In the retching phase, the abdominal muscles undergo coordinated contractions together with the diaphragm, but nothing is expelled. In the following (expulsive) phase, intense pressure is brought on the stomach by powerful contractions of both diaphragm and the abdomen. These contractions last much longer than a normal period of muscular contraction. The powerful contraction of the diaphragm causes it to move downwards, reducing thoracic pressure while increasing intraabdominal pressure. Then the upper esophageal sphincter relaxes, allowing expulsion of gastric contents under the high pressure built up around the stomach. The magnitude of this high pressure may be judged from the fact that in the ejection phase the thick viscous vomit does not dribble as in regurgitation, it may be ejected several feet (Projectile vomiting). During this process the ejection pressure also acts on the spleen and the vasculature supplying the intestine. Their contained blood will be driven into the Inferior Vena Cava and upwards in the superior vena cava, toward the head, producing hazardous superior vena caval pressures.

\section{Venous reflux}

How this pressure surge is distributed depends on the configuration of the head veins. Veins are much more variable in their configuration 
than arteries [13]. Figure 2 illustrates a typical configuration of some of those veins involved in retinopathy (Figure 2).

Each eye has two circulatory systems, the retinal and the vorticose. The retinal artery and vein supply a large proportion of the sensing elements and the Vorticose veins predominately drain the structure. Both ultimately drain into a cavernous sinus. A sinus is a groove in a bone in which a vessel may lie, or which may form part of a vessel. Actually, at the stage of bone development involved in apparent SBS cases, the skull is too thin to have significant grooves, so the cavernous sinus is more like a large vein, but with an internal trabeculae network preventing it from over distending. Normally, a cavernous sinus drains largely through inferior and superior Petrosal Sinuses and onwards to a jugular vein.

Now suppose a pressure surge arrives via the Superior Vena Cava. Then the left and right Brachiocephalic veins will convey that pressure to the valves in the left and right Jugular Vein Valves. Hsu [14] descibes the function of these valves as "The Internal Jugular Vein is a main extracranial route for venous drainage. The Jugular venous valves, which are located near the junction with the innomininant vein, prevent transmission of thoracic pressure and reflux of venous blood into the cerebral circulation. Jugular valve insufficiency could result in retrograde jugular venous flow and back transmission of central venous pressure."

In their study of closed-chest cardiac resusitation, Harmon and Edwards [15] studied valves in the internal jugular and subclavian veins. Normally the brain is protected from SVC pressure surges by valves in the jugular veins (Figure 2). However, in their cohort of 100 adult autopsy cases, valves were actually absent in the internal jugular veins of 9 cases that had lived apparently normal lives. Only in 87 cases were valves present in all four veins. In 13 cases, valves were anatomically absent from 16 veins, 9 of which were the left internal jugular vein. Retrograde flow of high-pressure venous blood into the brain veins would have occurred with any bouts of SVC hypertension. Where valves were present, $90 \%$ were bicuspid and $10 \%$ were unicuspid. Unicuspid valves were more common in the internal jugular veins than in the subclavian veins.

\section{Conclusion}

Summarising, the brain needs protection from pressure surges occurring in the SVC. In the majority of cases protection is provided by the valves in the inner jugular veins. Cerebral venous hypertensive injuries are to be expected if jugular vein valves are insufficient or absent. In many of the adult cases referenced here recovery was recorded as complete in a few months. If this occurs in Infant valsalva retinopathy the incidence of apparent SBS may be higher than it appears from the serious cases recognised. This study indicates that there is a form of retinopathy which occurs when and only when there is a surge in venous superior vena cava pressure in vulnerable subjects. The vulnerability factor is insufficiency or absence of valves in the inner jugular veins. An interesting follow-up study would be to determine the incidence of defective Jugular veins in suspected SBS.
- There is ample evidence from another discipline (Ophthalmology) that a mechanism exists (Infant Valsalva Retinopathy) in which retinal injuries similar to those specified in SBS will be expected to occur in some vulnerable individuals, The injuries are caused by a developmental defect, trauma is not involved

- Lord Justice Gage's acceptance that findings of retinal haemorrhages is powerful supporting evidence of shaking was based on the belief that retinal injuries had a unique cause. The well-established concept of valsalva retinopathy shows that there is at least one other mechanism producing the same retinal injury pattern.

- Hence, since retinal injury does not have a unique cause, findings of retinal haemorrhages can no longer be considered valid proof for any aetiology of SBS.

- Therefore, this element of the Triad is rendered invalid, and hence the Triad itself is invalid in its present form.

\section{References}

1. American Academy of Pediatrics (2001) Shaken baby syndrome: Rotational cranial injuries-Technical Report. Pediatrics 108: 206-210.

2. Carbaugh SF (2004) Understanding shaken baby syndrome. Adv Neonatal Care p: 4.

3. Gage IJ, Gross J, McFarlane J (2005) Supreme Court of Appeal. Neutral citation Number, EWCA Crim 1980 Case Nos:200403277, 200406902, 200405573, 200302848.

4. Duane TD (1972) Valsalva hemorrhagic retinopathy. Trans Am Ophthalmol Soc 70: 298-313.

5. Talbert DG (2014) The Legacy of John Caffey: Shaken baby or pyloric stenosis J Trauma Treat 3: 192

6. Kocak N, Kaynak S, Kaynak T, Oner HF, Cingil G (2003) Unilateral purtscherlike retinopathy after weight-lifting. Eur J Ophthalmol 13: 395-397

7. Jones WL (1995) Valsalva maneuver induced vitreous haemorrhage. J Am Optom Assoc 66: 301-304.

8. Ladjimi A, Zaouali S, Messaoud R, Ben Yahia S, Attia S, et al. (2002) Valsalva retinopathy induced by labour. Eur J Ophthalmol 12: 336-338.

9. Sbeity $\mathrm{H}$, Mansour AM (2004) Recurrant retinal vein occlusion after playing a wind instrument. Graefes Arch Clin Exp Ophthalmol 242: 428-431.

10. Georgion T, Pearce IA, Taylor RH (1999) Valsalva retinopathy associated with blowing balloons eye (Lond) 13: 686-687.

11. Roberts DK, MacKay KA (1987) Microhemorrhagic maculopathy associated with aerobic exercise. J Am Optom Assoc 58: 415-418.

12. https://en.wikipedia.org/wiki/Vomiting.

13. Talbert DG (2016) Cerebral venous malformation as a cause of neonatal intraventricular haemorrhage and unexplained infant subdural haemorrrhage. Anat Physiol 6: 5.

14. Hsu HY (2011) Jugular venous reflux and neurological disorders. Acta Neurol Taiwan 20: 1-3.

15. Harmon JV Jr, Edwards WD (1987) Venous valves in subclavian and interna jugular veins. Frequency, position, and structure in 100 autopsy cases. Am J Cardiovasc Pathol 1: 51-54. 